\title{
BMJ Open Patient experiences and perceptions of chronic disease care during the COVID-19 pandemic in India: a qualitative study
}

Kavita Singh (D) ,, ${ }^{1,2}$ Aprajita Kaushik, ${ }^{1,2}$ Leslie Johnson, ${ }^{3}$ Suganthi Jaganathan, ${ }^{2}$ Prashant Jarhyan (D) , ${ }^{1}$ Mohan Deepa, ${ }^{4}$ Sandra Kong, ${ }^{5}$ Nikhil Srinivasapura Venkateshmurthy (D) ,1,2 Dimple Kondal, ${ }^{1,2}$ Sailesh Mohan, ${ }^{1,2}$ Ranjit Mohan Anjana, ${ }_{4}$ Mohammed K Ali, ${ }^{6}$ Nikhil Tandon, ${ }^{7} \mathrm{~K}$ M Venkat Narayan, ${ }^{6}$ Viswanathan Mohan, ${ }^{4}$ Karen Eggleston, ${ }^{5}$ Dorairaj Prabhakaran ${ }^{1,2,8}$

To cite: Singh K, Kaushik A, Johnson L, et al. Patient experiences and perceptions of chronic disease care during the COVID-19 pandemic in India: a qualitative study. BMJ Open 2021;11:e048926. doi:10.1136/ bmjopen-2021-048926

- Prepublication history and additional supplemental material for this paper are available online. To view these files, please visit the journal online (http://dx.doi.org/10.1136/ bmjopen-2021-048926).

Received 11 January 2021 Accepted 14 May 2021

Check for updates

(C) Author(s) (or their employer(s)) 2021. Re-use permitted under CC BY-NC. No commercial re-use. See rights and permissions. Published by BMJ.

For numbered affiliations see end of article.

Correspondence to

Dr Kavita Singh;

kavita@ccdcindia.org

\section{ABSTRACT}

Objective People with chronic conditions are known to be vulnerable to the COVID-19 pandemic. This study aims to describe patients' lived experiences, challenges faced by people with chronic conditions, their coping strategies, and the social and economic impacts of the COVID-19 pandemic.

Design, setting and participants We conducted a qualitative study using a syndemic framework to understand the patients' experiences of chronic disease care, challenges faced during the lockdown, their coping strategies and mitigators during the COVID-19 pandemic in the context of socioecological and biological factors. A diverse sample of 41 participants with chronic conditions (hypertension, diabetes, stroke and cardiovascular diseases) from four sites (Delhi, Haryana, Vizag and Chennai) in India participated in semistructured interviews. All interviews were audio recorded, transcribed, translated, anonymised and coded using MAXQDA software. We used the framework method to qualitatively analyse the COVID-19 pandemic impacts on health, social and economic well-being. Results Participant experiences during the COVID-19 pandemic were categorised into four themes: challenges faced during the lockdown, experiences of the participants diagnosed with COVID-19, preventive measures taken and lessons learnt during the COVID-19 pandemic. A subgroup of participants faced difficulties in accessing healthcare while a few reported using teleconsultations. Most participants reported adverse economic impact of the pandemic which led to higher reporting of anxiety and stress. Participants who tested COVID-19 positive reported experiencing discrimination and stigma from neighbours. All participants reported taking essential preventive measures.

Conclusion People with chronic conditions experienced a confluence (reciprocal effect) of COVID-19 pandemic and chronic diseases in the context of difficulty in accessing healthcare, sedentary lifestyle and increased stress and anxiety. Patients' lived experiences during the pandemic provide important insights to inform effective transition to a mixed realm of online consultations and 'distanced' physical clinic visits.

\section{Strengths and limitations of this study}

- This study assessed the unintended health and economic consequences (loss of job and income) due to COVID-19 related lockdowns using qualitative methods.

> People with chronic conditions experienced a confluence (reciprocal effect) of COVID-19 pandemic and chronic diseases in the context of difficulty in accessing healthcare, sedentary lifestyle and high stress and anxiety. Stigmatisation and discrimination were reported by people who tested COVID-19 positive.

- An important limitation of the study is that the findings are solely based on self-reported impacts of the COVID-19 pandemic as the interviews were conducted over phone and we could not observe participant's non-verbal expressions.

\section{INTRODUCTION}

Living with chronic conditions during the COVID-19 pandemic has forced a rapid and dramatic change of where, when and how care is sought in order to reduce the risk of virus transmission. As of 10 March 2021, there have been more than 118 million confirmed cases and 2.6 million deaths due to COVID-19 worldwide. ${ }^{1}$ Of these, India accounts for $>11$ million confirmed cases and 158079 deaths. ${ }^{2}$ Several reports have confirmed that COVID-19 patients with pre-existing chronic conditions experience severe disease, worsened health outcomes, and higher mortality in comparison to those without. ${ }^{34}$ Hypertension and diabetes have been found to be the most prevalent comorbidities among patients infected with COVID-19. ${ }^{35-7}$ Although having a chronic disease increases one's vulnerability to COVID-19, patients' worsened health 
outcomes during the pandemic could be explained by unintended consequences of preventive measures (and lockdowns) to combat the pandemic. ${ }^{3}$ Lack of access to healthcare, poor treatment adherence and lack of selfcare due to the physical/social distancing, lockdowns, and disruption in outpatient services, may increase exposure to the chronic disease risk factors. ${ }^{3}$

India went into a nationwide lockdown on 25 March 2020 with most states in the country having extended the lockdown up until July 2020. Later on, some states still remained in lockdown or enforced night curfews. ${ }^{8}$ Limited socialisation, panic buying, disruption in essential services and rising fear of the unknown were a few ways in which the pandemic has had unintended adverse social, economic and psychological consequences. ${ }^{9}$ Heavy disruption in outpatient services due to the relocation of medical personnel has impacted access to healthcare, particularly for vulnerable populations such as the elderly and those with chronic conditions. ${ }^{3}$ People living in rural areas, for whom social distancing was difficult, have experienced barriers to getting tested or receiving treatment, including stigma, anxiety, fear, panic, denial and sleep disturbances. ${ }^{9-11}$

During pandemics, such as COVID-19, qualitative research allows us to better understand the underlying psychological effects and changes in health-seeking behaviours and lifestyle and can provide insights into aspects of behaviour and perceptions often missed in epidemiological and clinical research. ${ }^{12}$ Hence, given the high burden of chronic conditions in India, which are suboptimally controlled, and the increasing cases of COVID-19 and related mobility restrictions, it is important to study the impacts of COVID-19 pandemic on people with chronic conditions using qualitative methods. In this paper, we elicit the patients' lived experiences and perceptions of chronic disease care during the COVID-19 related lockdowns-with the main objective of helping us better understand the challenges faced by people with chronic conditions, their coping strategies, and the social and economic impacts the COVID-19 pandemic has had on their lives.

\section{METHODS}

\section{Study design}

We conducted an exploratory qualitative study to better understand how the COVID-19 pandemic has impacted the health, social and economic well-being of those with chronic conditions. Syndemic theory provided a framework to examine how mutually enhancing health issues, such as COVID-19 and pre-existing epidemics of chronic disease, operate within the context of social inequality given evidence that the pandemic differentially impacts populations based on demographic factors such as race, age, gender and socioeconomic status (SES) ${ }^{1314}$ Since our goal was to describe, and compare, contextual challenges and opportunities resulting from the COVID-19 pandemic in India, we drew insights through semistructured interviews with patients living with chronic conditions in different parts of India. We focused on the key challenges that were faced and the mitigators/lessons learnt during the COVID-19 related lockdowns. Recognising that socioecological and biological factors contribute to vulnerability to COVID-19 infection among people with chronic conditions, we purposively sampled participants to elicit diverse perspectives with respect to differences according to age group, sex, comorbidities and diagnosis of COVID-19.

\section{Study setting}

A diverse sample of 41 study participants-adults with chronic conditions, such as hypertension, diabetes, stroke, coronary artery disease and chronic kidney disease, and who varied based on select sociodemographic characteristics-who are currently enrolled in existing longitudinal cohort studies (ie, Centre for cArdiometabolic Risk Reduction in South-Asia (CARRS)-Surveillance Study ${ }^{15}$ and UDAY (A Comprehensive Diabetes and Hypertension Prevention and Management Program In India ${ }^{16}$ ) from four sites: Delhi, Haryana, Vizag and Chennai were invited and chose to participate in an in-depth phone interview.

\section{Data collection}

We conducted semistructured interviews over the phone between August and September 2020 using an interview guide specifically developed for patients living with chronic conditions (see online supplemental file 1 for the interview topic guide). The interview topic guide was pilot tested, and appropriate central training was provided to the interviewers to standardise data collection. The interview topic guide broadly focused on two aspects: (1) the challenges faced during the COVID-19 pandemic and its impact on participants' access to healthcare; lifestyle; mental health; employment and income; and self-care behaviours; and (2) the preventive health measures undertaken during the pandemic, lessons learnt from this situation, and any positive or negative changes. During the in-depth interviews, participants were asked about the time of diagnosis and/or length of treatment for their chronic condition(s); the challenges they faced during the pandemic; the difficulties faced in accessing healthcare facilities; the availability of medicines; the presence of fear, anxiety or stigma in seeking COVID-19 testing and treatment; the impact on their employment and income; and any key lessons learnt from the pandemic.

Five members of the study team (KS, SJ, Avinav, Kumar and Rajesh) - trained qualitative researchers-conducted the in-depth interviews until data saturation was achieved (ie, the point at which no new information emerged). Open-ended questions and probes were used to elucidate emerging themes and derive sufficient detail and context. An iterative approach was used for data collection and analysis based on the framework method for qualitative research. ${ }^{17}$ Interviews ranged from $10 \mathrm{~min}$ to $40 \mathrm{~min}$ in 
length. All interviews with participants were conducted in their local regional languages (Hindi, Telugu and Tamil).

\section{Data analysis}

Our research used the framework method to qualitatively analyse the interview data because it allows for comparisons across participant data while retaining the contextual information within individual narratives that shaped their experiences. ${ }^{17}$ All the in-depth interviews were audio-recorded, transcribed (verbatim), translated, anonymised and checked for accuracy. The first author and two other researchers (MG, APM) developed a codebook based on the interview guide, adding and coding for new concepts that emerged through iterations of data collection and analysis. A selection of the transcribed interviews was read and coded by two qualitative researchers for discussion with the co-authors to establish agreed on code definitions. Identified subthemes remained consistent throughout the analysis. We used MAXQDA software to code interview data and systematically compare coded segments and identified themes across interviewees. Our qualitative analyses focused on identifying the context, barriers and opportunities to better manage chronic conditions in the current healthcare system during the COVID-19 pandemic. We used illustrative non-attributable quotations.

\section{Patient and public involvement}

There was no patient involvement in the design and planning of this study. The interview topic guide was informed by our sample (ie, patients living with chronic diseases) and their vulnerability to COVID-19. Our aim was to explore their experiences, perceptions and the challenges faced by them during the pandemic. Study participants provided their verbal consent prior to participating in the in-depth interview. Participants were given the opportunity to ask questions. Overall, there were no to minimal risks involved. The results will be shared with the participants by dissemination through a study newsletter.

\section{RESULTS}

We interviewed 25 male and 16 female participants with an average age of 56 years. Three-fifth $(61 \%)$ of the participants pursued formal education until high school/ secondary school. More than half of the participants $(54 \%)$ reported being employed while $17 \%$ were retired as per the last follow-up survey conducted in the CARRS (2016) and UDAY (2019) cohorts. The most prevalent chronic conditions were diabetes $(71 \%)$ and hypertension $(73 \%)$, and $32 \%$ of the participants reported being moderately anxious or depressed. Of the $29 \%$ participants diagnosed or treated for COVID-19, 12\% reported being hospitalised for an average of 9 days (table 1).

We explored the social and psychological experiences of the participants and perceptions of chronic disease care during the pandemic using the framework method of
Table 1 Characteristics of study participants $(n=41)$

\begin{tabular}{|c|c|c|}
\hline Characteristics & & $\mathbf{N}(\%)$ \\
\hline $\begin{array}{l}\text { Age (in years), } \\
\text { mean } \pm S D\end{array}$ & & $56.3(10.8)$ \\
\hline Male & & $25(61 \%)$ \\
\hline \multirow[t]{4}{*}{ Educational status } & $\begin{array}{l}\text { College graduate and } \\
\text { above }\end{array}$ & $7(17 \%)$ \\
\hline & $\begin{array}{l}\text { High school/secondary } \\
\text { school }\end{array}$ & $25(61 \%)$ \\
\hline & Literate/primary school & $4(10 \%)$ \\
\hline & Illiterate & $5(12 \%)$ \\
\hline \multirow{3}{*}{$\begin{array}{l}\text { Employment } \\
\text { status }\end{array}$} & Employed & $22(54 \%)$ \\
\hline & Homemaker & $12(29 \%)$ \\
\hline & Retired & $7(17 \%)$ \\
\hline \multirow{3}{*}{$\begin{array}{l}\text { Household } \\
\text { income }\end{array}$} & $\leq 10000$ INR & $13(32 \%)$ \\
\hline & 10001-30 000 INR & $18(44 \%)$ \\
\hline & $\geq 30000$ INR & $10(24 \%)$ \\
\hline Diabetes mellitus & & $29(71 \%)$ \\
\hline $\begin{array}{l}\text { High blood } \\
\text { pressure }\end{array}$ & & $30(73 \%)$ \\
\hline Heart disease & & $10(24 \%)$ \\
\hline $\begin{array}{l}\text { Chronic kidney } \\
\text { disease }\end{array}$ & & $3(7 \%)$ \\
\hline Stroke & & $2(5 \%)$ \\
\hline $\begin{array}{l}\text { Chronic } \\
\text { obstructive } \\
\text { pulmonary } \\
\text { disease }\end{array}$ & & $2(5 \%)$ \\
\hline \multirow[t]{2}{*}{$\begin{array}{l}\text { Anxiety/ } \\
\text { depression }\end{array}$} & $\begin{array}{l}\text { Not worried or } \\
\text { depressed }\end{array}$ & $32(78 \%)$ \\
\hline & $\begin{array}{l}\text { Moderately anxious or } \\
\text { depressed }\end{array}$ & $9(22 \%)$ \\
\hline $\begin{array}{l}\text { Participant } \\
\text { diagnosed } \\
\text { or treated for } \\
\text { COVID-19 }\end{array}$ & Yes & $12(29 \%)$ \\
\hline $\begin{array}{l}\text { Hospitalised for } \\
\text { COVID-19 }\end{array}$ & & $5(12 \%)$ \\
\hline $\begin{array}{l}\text { No. of days } \\
\text { hospitalised, } \\
\text { mean } \pm \text { SD }\end{array}$ & & 9 (3.6) \\
\hline
\end{tabular}

INR, Indian rupees.

analysis. We found four themes that are summarised below. Exemplar quotes for each theme are displayed in table 2.

\section{Theme 1: challenges faced and impacts of the COVID-19 pandemic}

Feelings of fear, anxiety and stress associated with COVID-19

The majority of participants reported fear of contracting COVID-19. However, the fear associated with COVID-19 or feelings of stress/anxiety were more commonly experienced by women than men from Chennai. In Delhi, more 
Table 2 Major themes and illustrative quotes identified through in-depth interviews

$\begin{array}{ll}\text { Themes } & \text { Subthemes } \\ \text { Challenges faced } & \text { Feelings of fear, anxiety or stress } \\ \text { and impacts of } & \text { associated with COVID-19 } \\ \text { the COVID-19 } & \\ \text { pandemic } & \\ & \\ & \text { Impact on self-care behaviours, such } \\ & \text { as diet, exercise }\end{array}$
as diet, exercise

Illustrative quotes

'Yes. I was scared of that (covid). I had to do the (blood sugar) test. I was scared that I may not have this but because of someone else I may get affected. I went with the full safety and all. We have doubt to go to the hospital, to the doctor. I didn't want to get affected by this.' (U-D 02-D)

'everyone scares us saying that it is difficult for the diabetic. So, I didn't want that to happen. Because they had the spread the awareness that diabetics, old aged people have a problem during this corona. And yes, I was scared.' (U-K_05-D)

'...... Earlier, I was not able to eat on time and used to feel tired. Now, because of this COVID, I am taking my food on time and now I don't have any problem. Now, my sugar is normal, and tiredness is also not there. Because of maintaining time, I feel healthy.' (U-05-V) 'In the beginning during the first month I faced problem from COVID... When government had enforced restriction to not go out... so at that time I used to do some exercises which I know at home only.' (U-05-V)

'The income is stopped so this is natural worry. That's the tension which I have on every 3rd or 4th day.' (U-C_01-D)

'There was no issue with the health, but the mind was disturbed a bit. The work is not there, and I am not going for the job also. The salary is not coming fully and when we do stay at home then we will be irritated. That used to happen many times like at night till $2 \mathrm{am}$ or $3 \mathrm{am}$ I was not having sleep at all. Then it is also like if I sleep at 3am then I have to sleep till 8am or 9am or 10am also. I had to stay awake and I play games on mobile for 2 to 3 hours. I wake up at 5 am also.' (U-D_02-D)

'since, there has been lockdown, I am not able to go out for walks, at home how much will you walk, so that is not possible nowadays.' (U-J_04-D)

Impact on access to healthcare

'The medical shops were open all the time and government also did not restrict people who were going to medical stores right.' (U-08-V)

'I was not keeping well and none of the hospitals were taking any admission. They said that due to covid, beds are not available. And if you are ready to sleep on ground then we will take your admission..........' (U-08-V)

'We were afraid of meeting the doctor. There will be many patients in the hospital. We are afraid of this and because of that we don't go to meet doctor.' (U-09-C)

'I didn't go to the hospital. The corona was there, and that time hospital was not good to visit. I was saving myself.' (U-N_06_D)

'I didn't have any issue because all those services were open. The doctors were doing the check-ups online or on WhatsApp or on video calls also.' (U-S_09_D)

'in government hospitals I will have to run from place to place there and now since the corona is there, they don't listen to you at all.' (U-L_01-S)

Impact on employment and income 'We faced difficulties at home because I am into driving. Actually, I am driver. Before lockdown, I went home for some work. Because of lockdown, I had to stay at home for 2 months 15 days. I, my wife and children are jobless since then. There was no possibility of doing any work or going anywhere. We had a lot of trouble at that time. We could not go out. We just got along with what we have, taking help from relatives. That 2 months, 15 days, we faced difficulty.' (R-02-V)

Impact on lifestyle and socialising 'I only go out in case of some need. When there is work, only then I try and go out.' (UJ_04-D)

'It is difficult, but we don't go out at all. There was a death in the family for that also I could not go. My brother died; I could not go.' (U-10-C)

'We are not able to meet the daily expenses. Also, we have to run the house, whatever we earn goes in the daily grocery and vegetable needs.' (U-R_07-D)

'all the things are become very expensive. Life is tough now.' (R-S_06-S)

'I would say this has ended the humanity like we cannot meet anyone and support anyone. If we go to someone then we cannot go inside the house and we have to stand outside of the house. Earlier if we go to someone then they used to ask us to sit at home and ask for having tea or not. Now we cannot even ask anyone. They think that we don't know why people are behaving like this. If someone comes from outside, then people do not even take them inside the home also. We talk to the people standing outside and ask them to leave from there only.' (U-D_02-D)

Impact on other factors such as children's education

'No, they are not studying. You see, I am working, and my wife is also working, if we sit by their side, they are studying, we just advise them as much possible. So, that is the problem.' (U-02-C)

'They are sitting at home and learning online. we have to get the recharge for them for 200 or 250. So, that expenditure has increased.' (U-R 07-D)

'I agree that studies have suffered because studies weren't happening at all during the lockdown, as such schools are closed, what to do and what not, this definitely is a problem. that they couldn't study well, schools are closed, what the children can do.' (U-S_04-S)

'The outsiders feel that we are infected only. Whenever people used to come out, they behaved as if don't know what has happened. I used to feel that how these people are. But what can we say now about anyone?' (U-K_05-D)

the participants

diagnosed with

COVID-19 in the family and they should stay away from that family.' (U-D_08-S) 


\begin{tabular}{|c|c|c|}
\hline Themes & Subthemes & Illustrative quotes \\
\hline $\begin{array}{l}\text { Preventive } \\
\text { measures taken } \\
\text { during lockdown } \\
\text { /mitigators }\end{array}$ & & $\begin{array}{l}\text { 'We should follow social distancing. We should not go near to the person while talking. We } \\
\text { should wear masks. If we go and come back with all these safety measures, then we would } \\
\text { not be affected by it.' (U-09-C) } \\
\text { 'Earlier, when we used to bring vegetables, we used to keep in our fridge directly. Now, when } \\
\text { we go to bring vegetables in the market, we wear mask and use sanitizer and after coming } \\
\text { backing we keep all items under sun and wash it with the solution of turmeric, water and salt } \\
\text { and after drying we will keep it in the fridge. We are taking more care of our health after covid.' } \\
(U-05-V)\end{array}$ \\
\hline $\begin{array}{l}\text { Lessons learnt } \\
\text { from the } \\
\text { pandemic }\end{array}$ & & $\begin{array}{l}\text { 'It is good to be safe. We should avoid going out often to be safe because we don't know who } \\
\text { are infected.' (U-01-C) } \\
\text { 'We have to be careful from the corona and we have to be safe from this. That's the only } \\
\text { medicine now.' (U-C_01-D) }\end{array}$ \\
\hline
\end{tabular}

men experienced fear, stress, anxiety associated with COVID-19 than women. The proportions remained the same for the other two sites: Sonipat and Vishakhapatnam.

We have fear about death. When we hear about things that are happening, we also had tension and anxiety. (female participant, 47 years old)

Some participants were afraid of visiting the hospitals and doctors as they may contract the infection from there. Participants also reported having pre-existing chronic diseases and/or being in an older age bracket as concerning factors as they felt they may have higher risk of getting infected. Perceptions of how the virus is transmitted also shaped feelings of fear as a few participants reported they thought the virus was air-borne and were afraid of getting the infection this way.

I was afraid of corona, in the neighbour's house there was corona. They said it will spread through air, we have small kids in home so, we didn't allow the kids to play outside. As soon as we saw (them) we got fear. (female participant, 42 years old)

In addition, most participants reported feeling stressed and had difficulty sleeping due to a loss in income. Some participants reported that they were positive for COVID19 , but there was no need to worry since they were taking all necessary precautions.

\section{Impact on self-care behaviours (diet and exercise)}

A few of the participants reported positive changes to their diets such as increasing their intake of vegetables and eggs. Some participants expressed that they consumed less non-vegetarian food items, either out of safety concerns or due to lack of availability during the lockdown. One participant expressed that being at home during the lockdown enabled him to have regular meals on time. Positive changes to diet were commonly reported. Participants reported finding alternatives to their exercise routines such as walking on the terrace; however, no significant change was reported in terms of improving self-care and activities/hobbies undertaken during the lockdown from the Delhi and Sonipat sites.
I used to go for a walk daily earlier but now I'm unable to go. Now I am walking in our terrace. (male participant, 58 years old)

However, most refused to indulge in any exercise during the lockdown. Particularly, participants who have diabetes and hypertension, feared going out for a walk due to their underlying conditions.

\section{Impact on access to healthcare}

Most participants reported they did not feel the need to visit a hospital; however, those who did avoided it. There were no major striking differences observed across gender, age, or site for the following themes: access to healthcare/medicines, worsening of hypertension or diabetes symptoms during the pandemic, COVID-19 diagnosis and care. Among those who accessed healthcare, no one reported major complaints during the lockdown as they were able to consult their treating doctors via phone or WhatsApp. A few participants even arranged a tele or video consultation. Some of the participants expressed difficulty in accessing government health facilities due to outdoor patient services (OPDs) being dysfunctional during the lockdown. Others avoided visiting government health facilities due to fear of contracting the infection. The few participants who tried to visit a hospital were advised against doing so by the hospital staff, unless it was an emergency. Further, medicines remained out of stock at government pharmacies, particularly in Sonipat and rural Vishakhapatnam.

But they say that they would give medicine only if doctors say so. But we feel afraid of going to hospital. If we go to hospital, then they (hospital staff) would touch us. We are afraid of this. (male participant, 54 years old)

One participant reported that they had difficulty getting medicines from the government hospital, stating: 'They are saying that the medicine (stock) has not come yet. So, I asked them to write down the medicines so that I can buy from medical shop.' (male participant, 56 years old) 
However, most participants reported that medicines could be easily bought from pharmacies closer to their homes. Those who were unable to buy medicines themselves asked others to buy for them. Unlike in other sites, participants in Chennai reported getting their blood sugar tested during the lockdown, either at home or at a lab.

\section{Impact on employment and income}

Almost all of the participants reported that the lockdown impacted their employment status and income. The selfemployed participants expressed concerns regarding their incomes as they had to shut down shops during the lockdown and experienced fewer buyers post lockdown. Lack of transportation to go to work was another barrier for a few participants. Further, more women reported an effect on income or financial hardships in Chennai, but greater proportion of men experienced loss of income or job from Delhi and Vishakhapatnam. No such differences were observed in participants interviewed from Sonipat. Others reported a reduction in income or salary despite having a job. One participant who was a bus driver reported having no work during the lockdown period, while a participant who was a carpenter reported not going to work even if there were upcoming jobs, due to fear. Another participant expressed that she had to sell some 'items' for her family's survival, as she was not earning an income and her son provided the only source of income from running a rickshaw, which too was insufficient.

During the lockdown more participants from Chennai, and only one each from Delhi and Sonipat reported receiving financial aid from the government in the form of monetary help (approximately 1500 rupees or US\$20) and free rations, while none from Vishakhapatnam. One of the participants also reported receiving free medicines from the health centres set up by the state government.

\section{Impact on lifestyle and socialising}

Almost all participants reported that they reduced outdoor activities and socialising. They either avoided or were unable to attend social gatherings, such as weddings, due to the restrictions imposed by the government, lack of transport, or fear. Some participants reported that they were unable to attend the deaths of their immediate family members.

It is difficult, but we don't go out at all. There was a death in the family for that also I could not go. My brother died; I could not go (Female participant, 44 years old)

They also reported significant changes in their lifestyle due to the lockdown, such as reducing expenses due to strained household finances and restricting their diets in terms of fruits and dairy. Some also blamed price inflation for compounding the adverse impact on their living standards. A participant reported intaking less vegetables during the pandemic due to increased costs, stating:
'The rates (of essential supplies) were high (during the pandemic). Grocery shop, fish shop, vegetable shops were all charging high.' (female participant, 52 years)

\section{Impact on other factors (children's education)}

Most participants expressed concerns over the impact of COVID-19 on their children's education. Most participants reported that their children were attending online classes, while others reported that theirs stopped classes due to a lack of income or money to pay for the internet. Children who were in boarding schools were sent back home. Most participants, however, were not satisfied with their children pursuing their studies online. One participant expressed that children were not being attentive, and someone had to sit beside them while studying. When asked, Do they have online classes?', a participant responded: They have but I am not much satisfied. You see, I am working, and my wife is also working, if we sit by their side, they are studying, we just advise them as much possible.' (male participant: 45 years old)

Another participant stated that education should only be sought at school just as one seeks God in the temple. Another participant opined that children have lost 1 year of education because of the pandemic: 'As far as education is concerned, it is a year of loss.' (female participant, age: 47 years) Another one expressed concern about sending their children back to school once they reopen due to fear of COVID-19. Educated mothers reported teaching their children at home.

\section{Theme 2: experience of the participants diagnosed with COVID-19}

Participants who were diagnosed with COVID-19 mostly had mild symptoms-cough and fever. The common mode of treatment was hospital admission with medication before returning home or self-quarantining elsewhere. When asked about their treatment by doctors or hospital staff, one participant responded,

Doctor use to come in the morning and ask everyone personally if we are having any problem. Whether we have any headache or body pains. Also, ask everyone personally if we are feeling dizzy, or any other problem and he used to give medicines to everyone separately according to their problems. Covid related medicines were given in the morning for taking 2 times a day. (male participant: age: 63 years)

Another participant reported that she stayed in a separate room at her home and took all necessary precautions to avoid spreading her infection to other family members. A few of the participants reported that they faced discrimination after they were cured, and that neighbours stopped talking to them or behaved in a strange manner towards them.

Everyone in the family had Corona, me and aunty were safe. Both my son, their wives and even my grandchildren. Only our reports were negative. We got it checked in the hospital... You cannot stop 
someone, they might have said something, that corona has spread in the family and they should stay away from our family. (male participant, age: 63 years)

Death was also experienced first-hand by participants whose families became infected. One participant reported that there were three deaths in their family due to the infection.

Whoever got infected, expired. My uncle's son got infected. My aunt got infected, she expired and later my sister-in-law was infected, she too died. (female participant, age: 48 years)

\section{Theme 3: preventive measures taken during lockdown or mitigators}

Almost all participants reported undertaking the three main preventive measures-using face masks and maintaining social distancing, keeping personal hygiene, and cleaning vegetables, fruits and other grocery items. Some participants also reported using gloves or face shields to protect themselves when they went out. An increase in frequent hand washing and use of sanitizers was reported. Some participants emphasised that they practised taking a bath as soon as they returned home.

I am going out then it is like washing hand with soap and wearing mask also. I have to be away from the people while talking to anyone and keep distance of 2-3 feet. I have stopped doing handshake and then it is like when I come from outside then I will wash the hand and face with soap and water. (Male participant, age: 45 years)

Most participants reported that they avoided leaving their homes unless necessary. A few participants mentioned taking other measures such as steam inhalations, drinking herbal juices, decoction (kadha), and hot water. One participant, a driver, reported that he always kept a mask on while driving and asked his passengers to do the same.

\section{Theme 4: lessons learned from the pandemic}

Almost all participants stressed the continued importance of wearing masks, washings hands, or using sanitizers. While some participants expressed not having given any thought to how things would be like post-pandemic, most participants expressed that they considered the changes brought by the pandemic positively and that they embraced the improved practice of cleanliness. When asked if anything positive happened because of the pandemic, one participant responded,

Pollution level has reduced a lot. I like these things had happened due to Covid situation. Luxury has been reduced. (female participant, age: 53 years)

Some participants reported that they experienced less pressure due to the COVID-19 pandemic and were able to spend more time with their families. Almost all the participants expressed that they would continue wearing masks and washing their hands regularly even post-pandemic.

Figure 1 is a schematic representation of the challenges and opportunities in chronic disease management during the COVID-19 pandemic. The major challenges faced during the pandemic and their impacts on healthcare, lifestyle and income and employment, presented in the figure are based on this study findings. The potential impact on disease outcomes and mental wellbeing and the solutions/novel opportunities in chronic disease management have been derived from published studies. $^{3410}$

\section{DISCUSSION}

To the best of our knowledge, this is the first study to investigate the lived experiences of patients with chronic conditions during the COVID-19 pandemic in India and the impact it had on their health, social and economic well-being using qualitative research methods. We summarised our findings into four themes: challenges faced during the COVID-19 pandemic, experiences of participants diagnosed with COVID-19, preventive measures taken or mitigators, and lessons learnt from the pandemic.

The underlying fear of uncertainty; feelings of helplessness; impact on income, employment, and lifestyle; and the threat of contracting the virus contributed to negative feelings of fear, anxiety, stress, anger and denial. These findings were in line with previous studies. ${ }^{10} 1118$ In this study, participants reported refusing testing or treatment as they believed that COVID-19 was just a way of god punishing humans for their sins. Fear, anxiety and other mental health implications could be attributed to loneliness due to a lack of social interaction, misinformation, and information overload through media/social media platforms. ${ }^{3}$ In our study, this was apparent when participants reported thinking the virus was airborne. Feelings of grief, sadness or depression could be attributed to the loss of a loved one or financial turmoil. ${ }^{10}$

In the present study, we found participants from the rural sites experienced difficulties in accessing healthcare or medicines, which is consistent with previous studies that suggest rural cities facing more severe impacts during the pandemic in comparison to urban areas due to a lack of healthcare facilities, as well as a low physicianpatient ratio. ${ }^{19}$ The pandemic economically impacted most participants, whether it was due to a lack of employment, reduction in salary, or market inflations, and the impact was found to be similar across the four sites. The impact on the lifestyle of participants was explicit as well, with most participants reducing socialising, especially in outdoor settings.

Participants infected with COVID-19 reported experiencing discrimination from neighbours after they recovered. This sheds a light on the issue of stigma related to the disease. Such behaviours of stigmatisation have also 
CHALLENGES AND OPPORTUNITIES IN CHRONIC DISEASE CARE DURING THE COVID-19 PANDEMIC

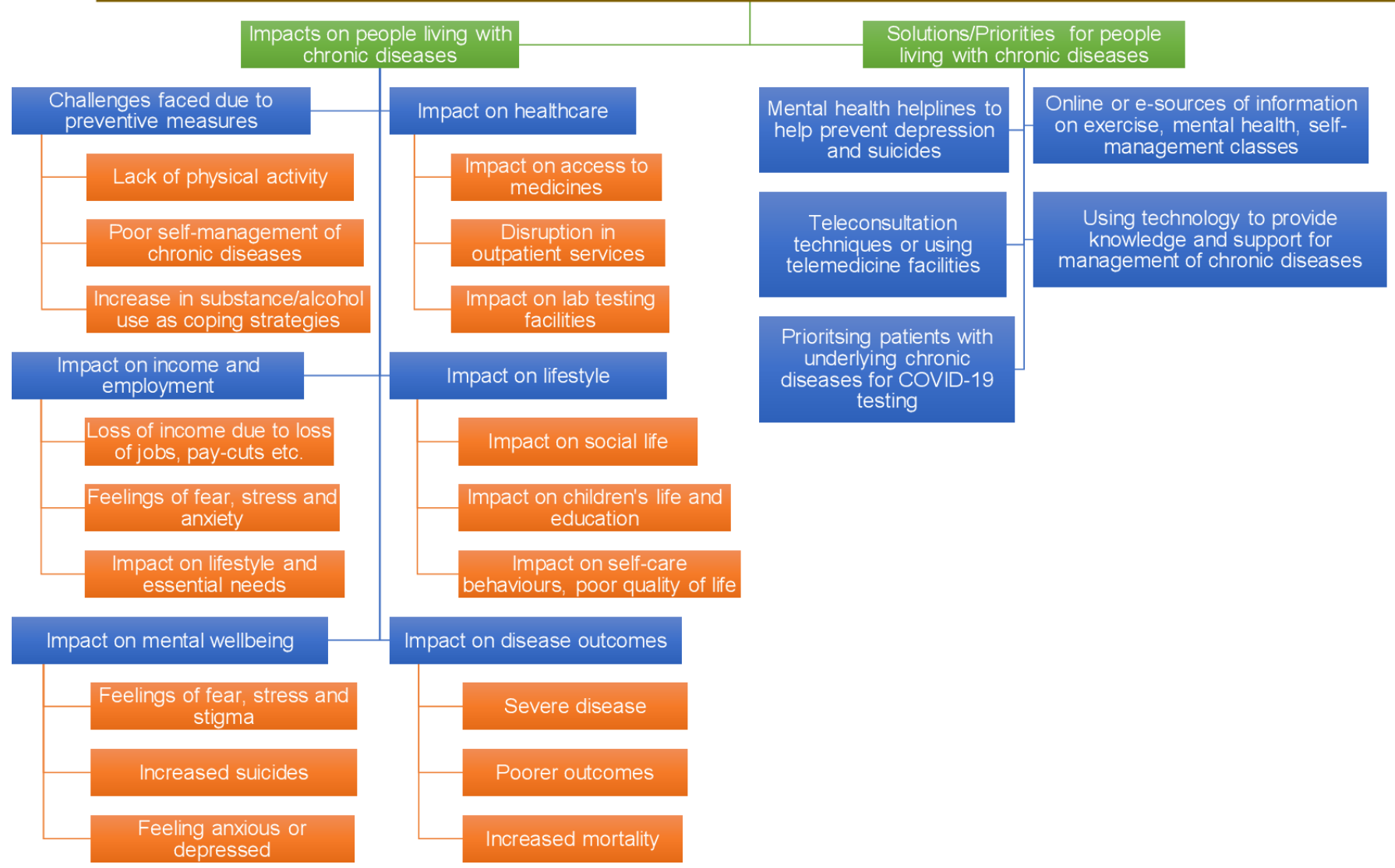

Figure 1 Schematic representation of the challenges and opportunities in chronic disease care during the COVID-19 pandemic.

been previously reported-'The increasing frequency of the negative social trend of stigma is causing a significant barrier to social inclusion and treatment delivery. When a person is reported as positive for COVID-19, he/ she is sometimes singled out, blamed and can be asked to leave the locality'; but how stigmatisation and negative behaviours affect the mental health of those infected needs further exploration. ${ }^{9}$

In the present study, a major challenge of the pandemic was an increase in time spent indoors-a causative factor for the rise in common risk factors of chronic diseases, such as lack of exercise, stress, increased use of alcohol/ substance abuse, or inadequate access to medicines. ${ }^{4}$ This study reports only an increase of sedentary lifestyles. Negative feelings such as stress, anxiety and lack of sleep were reported. Recent studies highlight that the largest percentage increase in excess deaths were noted in vulnerable and marginalised population, particularly among those with mental health problems. Quarantine/ isolation, social distancing, business closures and the increase in stress due to living through a pandemic are commonly reported factors that are impacting adverse health outcomes. This intersection of biological and socioecological factors contributing to the intensified effects of the pandemic among those already marginalised or vulnerable is referred to as a 'syndemic'. People living with chronic conditions are experiencing a syndemic in which the COVID-19 pandemic exacerbates their preexisting chronic condition, already occurring alongside other potentially marginalising sociopolitical and ecological factors, which contributes to poor health outcomes. This syndemic phenomenon has been reported from other countries like Brazil, Italy, Spain, Pakistan and the USA. $^{420-23}$

In order to better aid people with chronic conditions in overcoming impacts of the pandemic, particularly for elderly, basic interventions should be applied using innovative digital healthcare solutions such as mHealth, education/training on self-monitoring of blood pressure and blood glucose at home involving trained nonphysician health workers. Further, those at high risk should be actively encouraged to monitor their symptoms, practice self-care, adhere to medication, seek counselling for their mental health, and pursue virtual or teleconsultations when required. Providing information on self-managing chronic diseases and COVID-19 through short messaging services and social media platforms could be beneficial when access to healthcare is affected by mobility restrictions as well as an underlying fear of contracting the virus. ${ }^{3}$ Recovered patients with COVID-19 should be encouraged to spread information on health and self-care management and help lessen stigma around 
the disease. Encouraging people to spend more time with the elderly and children as well as learning to avoid misinformation related to COVID-19 circulating on social medial platforms can be effective steps to curb feelings of loneliness, stress and anxiety. Initiatives for interventions regarding mental health awareness during the pandemic have been pursued by various state governments in India. Broadcasting these on regional news channels or through text messages can be effective strategies and improve outreach. ${ }^{10}$ Recognising the 'syndemic' and 'reciprocal effect' COVID-19 and chronic conditions have on each other, there is a need to address misinformation and fake news, especially on social media, as it fuels fear and panic. Lastly, as indicated by previous studies, low SES is a major underlying factor for psychosocial distress and response to the pandemic. ${ }^{24}$ Therefore, further research is warranted to shed light on the long-term psychological, health and socioeconomic impacts of COVID-19 pandemic among vulnerable or marginalised population. ${ }^{25} 26$

\section{Strengths and limitations}

Through the analysis and interpretation of telephonic in-depth interviews, we have provided insights into the lives of those with pre-existing chronic conditions during the COVID-19 pandemic and shed light on how the interaction of these conditions introduced additional challenges to accessing care while also providing an impetus for some positive lifestyle changes. In particular, the findings of this study describe the impact of COVID-19 on access to healthcare as well as on individual's psychosocial and economic well-being. A unique strength of this study is that it does not focus on the reporting of solely negative feelings experienced during the pandemic. This study also has important limitations. First, the study findings are based on self-reported impacts of COVID-19 (ie, job loss or income loss), and authors could not verify these with objective measures or ethnographic observations. Second, interviews were conducted over telephone, which may have limited our understanding of patient experiences as the researchers could not observe non-verbal expressions. Lastly, only few participants in our study sample had confirmed diagnosis of COVID-19, so we could not explore the direct psychological and economic effects of COVID-19 across subgroups and the potential role of public and private health facilities to cater to the healthcare needs of population during pandemic, which merits further evaluation.

In conclusion, the implementation of COVID-19 related lockdowns adversely affected the health, psychosocial and economic well-being of people with chronic conditions. As health authorities have now resumed some elements of physical outpatient care for people with chronic diseases, this is an opportune time to gain insights from patients' lived experiences during the pandemic to creatively adapt and revitalise healthcare delivery. Health systems have an opportunity to not only adapt workflows but also leverage new forms of service delivery, such as virtual or teleconsultations involving trained and supervised non-physician health workers, to safely support patients with chronic conditions at a time when traditional in-person care increases risk of transmission.

\section{Author affiliations}

${ }^{1}$ Centre for Chronic Conditions and Injuries, Public Health Foundation of India, New Delhi, India

${ }^{2}$ Clinical Research, Centre for Chronic Disease Control, New Delhi, India

${ }^{3}$ School of Medicine, Emory University, Atlanta, Georgia, USA

${ }^{4}$ Department of Epidemiology, Madras Diabetes Research Foundation \& Dr. Mohan's Diabetes Specialities Centre, Chennai, India

${ }^{5}$ Shorenstein Asia-Pacific Research Center, Stanford University, Stanford, California, USA

${ }^{6}$ Rollins School of Public Health, Emory University, Atlanta, Georgia, USA ${ }^{7}$ Departement of Endocrinology and Metabolism, All India Institute of Medical Sciences, New Delhi, India

${ }^{8}$ Department of Epidemiology, London School of Hygiene and Tropical Medicine, London, UK

\section{Twitter Leslie Johnson @LesMunozJohnson}

Acknowledgements The authors gratefully acknowledge Avinav Prasad Maddury, Mareesha Gandral, Rajesh Khatkar and Kumar Munusamy for their assistance with data collection. The CARRS Study was funded in part by the National Heart, Lung, and Blood Institute (NHLBI), National Institutes of Health (NIH), Department of Health and Human Services, under Contract No. HHSN268200900026C, and the United Health Group, Minneapolis, MN, USA. UDAY is supported by an unrestricted educational grant from Eli Lilly and Company under the Lilly NCD Partnership Program. KS is supported by funding from the Fogarty International Centre, National Institutes of Health (NIH), United States (grant award: 1K43TW011164). NSV is supported by the Fogarty International Centre and National Institute of Mental Health, of the National Institutes of Health under Award Number D43 TW010543. KMVN, and MKA, were funded in part by the National Institute of Diabetes and Digestive and Kidney Diseases of the National Institutes of Health under Award Number P30DK111024. DP was supported by Fogarty International Centre of the National Institutes of Health under Award Number U01TW010097. The funding agency had no role in the design, conduct, or analysis of the study, and no role in the decision to submit the manuscript for publication. The content is solely the responsibility of the authors and does not necessarily represent the official views of the National Institutes of Health. KE gratefully acknowledges funding from the Stanford Asia Health Policy Program, Asia-Pacific Research Centre faculty research award, and a seed grant from the Stanford Centre for Asian Health Research and Education.

Contributors KE, KS, SM and DP contributed to the conception and design of the study. SJ, DK, MD, NSV, PJ, KS, DP, KE, KMVN and MKA had a role in acquisition, analysis or interpretation of data. KS and AK drafted the manuscript, and all authors critically revised the manuscript. DP, KE, MKA, NT, VM, ARM, LJ and KMVN provided technical and material support. All authors approved the final manuscript.

Funding The authors have not declared a specific grant for this research from any funding agency in the public, commercial or not-for-profit sectors.

Competing interests None declared.

Patient consent for publication Not required.

Ethics approval This study is approved by the institutional ethics committees of Centre for Chronic Disease Control (reference number: CCDC_IEC_11_2020) dated 01 July 2020, and Madras Diabetes Research Foundation, Chennai in the ethics approval letter dated 15 June 2020.

Provenance and peer review Not commissioned; externally peer reviewed.

Data availability statement Data are available upon reasonable request. All data relevant to the study are included in the article.

Supplemental material This content has been supplied by the author(s). It has not been vetted by BMJ Publishing Group Limited (BMJ) and may not have been peer-reviewed. Any opinions or recommendations discussed are solely those of the author(s) and are not endorsed by BMJ. BMJ disclaims all liability and responsibility arising from any reliance placed on the content. Where the content includes any translated material, BMJ does not warrant the accuracy and reliability of the translations (including but not limited to local regulations, clinical guidelines, terminology, drug names and drug dosages), and is not responsible for any error and/or omissions arising from translation and adaptation or otherwise.

Open access This is an open access article distributed in accordance with the Creative Commons Attribution Non Commercial (CC BY-NC 4.0) license, which permits others to distribute, remix, adapt, build upon this work non-commercially, and license their derivative works on different terms, provided the original work is 
properly cited, appropriate credit is given, any changes made indicated, and the use is non-commercial. See: http://creativecommons.org/licenses/by-nc/4.0/.

\section{ORCID iDs}

Kavita Singh http://orcid.org/0000-0003-4330-666X

Prashant Jarhyan http://orcid.org/0000-0002-5020-3995

Nikhil Srinivasapura Venkateshmurthy http://orcid.org/0000-0003-4037-6371

\section{REFERENCES}

1 WHO. Coronavirus disease (COVID-19), 2020. Available: https:// www.who.int/emergencies/diseases/novel-coronavirus-2019

2 covidindia. COVID-19 tracker updates for India for state wise \& district wise data, 2020. Available: https://www.covid19india.org/

3 Yadav UN, Rayamajhee B, Mistry SK, et al. A Syndemic perspective on the management of non-communicable diseases amid the COVID-19 pandemic in low- and middle-income countries. Front Public Health 2020;8:508.

4 Thakur JS, Paika R, Singh S, et al. COVID-19 and noncommunicable diseases: impact and the strategic approaches. Int $J$ Noncommun Dis 2020;5:29.

5 Singh AK, Misra A. Impact of COVID-19 and comorbidities on health and economics: focus on developing countries and India. Diabetes Metab Syndr 2020;14:1625-30.

6 Bhandari S, Singh A, Sharma R, et al. Characteristics, treatment outcomes and role of hydroxychloroquine among 522 COVID-19 hospitalized patients in Jaipur City: an Epidemio-Clinical study. $J$ Assoc Physicians India 2020;68:13-19.

7 Laxminarayan R, Wahl B, Reddy Dudala S. Epidemiology and transmission dynamics of COVID-19 in two Indian states, 2020 Available: http://science.sciencemag.org/

8 The Economic Times. Combating Covid-19: centre rushes highlevel teams to up, Punjab and Himachal, 2020. Available: https:// economictimes.indiatimes.com/news/politics-and-nation/combatingcovid-19-centre-rushes-high-level-teams-to-up-punjab-andhimachal/articleshow/79350236.cms

9 Mukherjee A, Bandopadhyay G, Chatterjee SS. COVID-19 pandemic: mental health and beyond - the Indian perspective. Ir J Psychol Med 2021;38:140-4.

10 Roy A, Singh AK, Mishra S. Mental health implications of COVID-19 pandemic and its response in India. Int J Soc Psychiatry 2020:1-14.

11 Nilima N, Kaushik S, Tiwary B, et al. Psycho-Social factors associated with the nationwide lockdown in India during COVID- 19 pandemic. Clin Epidemiol Glob Health 2021;9:47-52.
12 Vindrola-Padros C, Chisnall G, Cooper S, et al. Carrying out rapid qualitative research during a pandemic: emerging lessons from COVID-19. Qual Health Res 2020;30:2192-204.

13 Wiley. Introduction to Syndemics: a critical systems approach to public and community health, 2021. Available: https://www.wiley. com/en-us/Introduction+to+Syndemics $\% 3 A+A+C r i t i c a l+S y s t e m s+$ Approach+to+Public+and+Community+Health-p-9780470472033

14 Bambra C, Riordan R, Ford J, et al. The COVID-19 pandemic and health inequalities. J Epidemiol Community Health 2020;74:jech2020-214401-8.

15 Nair M, Ali MK, Ajay VS, et al. CARRS surveillance study: design and methods to assess burdens from multiple perspectives. BMC Public Health 2012;12:701.

16 Mohan S, Jarhyan P, Ghosh S, et al. UDAY: a comprehensive diabetes and hypertension prevention and management program in India. BMJ Open 2018;8:e015919.

17 Gale NK, Heath G, Cameron E, et al. Using the framework method for the analysis of qualitative data in multi-disciplinary health research. BMC Med Res Methodol 2013;13:117.

18 Sun N, Wei L, Shi S, et al. A qualitative study on the psychological experience of caregivers of COVID-19 patients. Am J Infect Control 2020;48:592-8

19 Kundu B, Bhowmik D. Societal impact of novel corona virus (COVID -19 pandemic) in India https://ideas.repec.org/p/osf/socarx/vm5rz. html

20 Mendenhall E. The COVID-19 syndemic is not global: context matters. The Lancet 2020;396:1731.

21 Islam N, Lacey B, Shabnam S. Social inequality and the syndemic of chronic disease and COVID-19: county-level analysis in the USA. $J$ Epidemiol Community Health 2021. doi:10.1136/jech-2020-215626. [Epub ahead of print: 05 Jan 2021].

22 Fronteira I, Sidat M, Magalhães JP, et al. The SARS-CoV-2 pandemic: a syndemic perspective. One Health 2021;12:100228.

23 Shim RS, Starks SM. COVID-19, structural racism, and mental health inequities: policy implications for an emerging Syndemic. Psychiatr Serv 2021:appi.ps.2020007.

24 Singh K, Kondal D, Mohan S, et al. Health, psychosocial, and economic impacts of the COVID-19 pandemic on people with chronic conditions in India: a mixed methods study. BMC Public Health 2021;21:685.

25 Rehman U, Shahnawaz MG, Khan NH, et al. Depression, anxiety and stress among Indians in times of Covid-19 Lockdown. Community Ment Health J 2021;57:42-8.

26 Mahure PK, Rairker AB, Kapoor GA. Impact of the COVID-19 pandemic on mental health: a cross sectional study. Indian Journal of Mental Health 2020;7:238-45 https://indianmentalhealth.com/pdf/ 2020/vol7-issue3/11-COVID-Related-Original-Research_Impact-ofthe-COVID.pdf 